\title{
TEATRO LATINOAMERICANO DE LOS VEINTE: UNA PRACTICA TEATRAL MODERNIZADORA
}

POR

\author{
OSVALDO PELLETTIERI \\ $U B A-C O N I C E T$
}

Este trabajo estudiarála peculiaridad del teatrolatinoamericano, originado en el sistema ${ }^{2}$ teatral culto ${ }^{3}$ de los veinte, desde el punto de vista de la historia interna del géneroy sus relaciones con los nuevos públicos. Dicha peculiaridad consiste en una profunda modernización textual, sin llegar a producir la ruptura del sistema como propiciaba la vanguardia histórica europea.

Estudiaremos entonces:

1. El sistema teatral anterior.

2. Los caracteres de la enunciada modernización ${ }^{4}$ en las grandes ciudades latinoamericanas.

\footnotetext{
${ }^{1}$ Para la obra dramática y la obra teatral y su sistema es aplicable lo que afirma Ana Pizarro con relación a la literatura (1985, 19): "Aquello que llamamos literatura latinoamericana constituye en realidad un conjunto formado por lo menos por dos o tres sitemas literarios diferentes, según las regiones, que provienen de sistemas culturales en general bastante diferenciados".

2 Al hablar de sistema literario y por extensión sistema teatral, aludimos a lo que comúnmente se denomina tradición teatral. Tinianov $(1970,89-101)$ distingue sistema -texto o conjunto de textos que se convierten en modelo para la producción de nuevos textos en un determinado período de la historia, cuya nota dominante es su dinamismode tradición, que desde el punto de vista del teórico ruso se caracteriza por su estatismo. Con relación a sistema literario y su vínculo con otras series sociales puede verse Guillén (1971); Villegas (1984, 5-40); de Toro (1986); Altamirano y Sarlo (1983, 15-32).

${ }^{3}$ Somos concientes de la necesidad de analizar los sistemas indígenas y populares; en este sentido coincidimos con el Informe Final de la Primera Reunión de Expertos del Proyecto de Historia de la Literatura Latinoamericana coordinado por Ana Pizarro (1984, 263).

${ }^{4}$ Nuestro método de trabajo está basado en el estudio de la producción, circulación y recepción de textos en Latinoamérica a partir de Tinianov (1968), quien señala tres etapas de la evolución literaria: en un primer momento, el principio constructivo automatizado confronta con un nuevo principio contrapuesto. En un segundo momento, el nuevo principio constructivo busca aplicaciones más amplias constituyendo el imperialismo del principio constructivo. El tercer momento marca la automatización del principio constructivo y la aparición de uno nuevo. A. Fowler (1971) establece tres fases en la evolución y la transformación de un género, a partir de la noción de género y cambio genérico. De Toro agrega el nivel contextual que explica por qué cambia el sistema en contacto con la serie social a partir de la situación cultural general, la situación política y el lugar que ocupa el artista en una sociedad de clases (1986, 201 y sigs.)
} 
1. Para comprender la modernización de los '20 es necesario primero describir brevemente el sistema teatral anterior y establecer sus relaciones con el nuevo sistema. Para ello realizaremos un corte sincrónico a mediados de la década del veinte en el teatro latinoamericano. Especialmente en las grandes ciudades - Buenos Aires, México, Santiago de Chile, La Habana subsistema hegemónico - culto-de enorme poder económico. Era un completo circuito teatral constituido por salas, autores, actores, público y crítica ${ }^{6}$.

Este subsistema realista-costumbrista, que incluía lo melodramático, era finisecular en América Latina y entroncaba con el origen de su teatro. Se puede decir que perdura en nuestro continente hasta la actualidad, de manera remanente, como discurso teatral desplazado, dejado de leer como estético por los sectores hegemónicos de la cultura.

Su surgimiento coincide con la formación de las burguesías, la aparición de nuevas fuerzas sociales -como la inmigración - y el advenimiento en las ciudades mencionadas de un campo intelectual relativamente autónomo del campo de poder. A la aparición de las instituciones mediadoras le sigue la del estímulo externo del naturalismo europeo que otorga otra función al realismo finisecular.

Entre los creadores se destaca Florencio Sánchez, dramaturgo uruguayo, que concretó una obra de enorme productividad en el Río de la Plata y de gran proyección en el resto de Latinoamerica. La intertextualidad de Sánchez marcó en su momento al subsistema popular en autores como el argentino Armando Discépolo, y es advertible todavía al final de la década del cuarenta en piezas como $\mathrm{El} \mathrm{puente,} \mathrm{de} \mathrm{Carlos} \mathrm{Gorostiza.} \mathrm{Este} \mathrm{subsistema} \mathrm{popular} \mathrm{está} \mathrm{presente,}$ con sus peculiaridades, en México, Cuba y Chile.

En el modelo canónico de este teatro: Barranca abajo (1905), luchan por obtener la primacía dos principios constructivos: el del realismo finisecularlo sentimental-, y el del naturalismo europeo -el artificio del encuentro personal-.

A nivel de la acción o estructura profunda ${ }^{7}$ el sujeto entra en acción con el fin de recuperar su honra social. La sociedad lo destina para que cumpla esa

\footnotetext{
${ }^{5}$ Lo que Antonio Candido denomina coaliscencias: "situaciones paralelas de los procesos literarios en América Latina encuentran muchas veces desde una perspectiva histórica momentos de aglutinamiento que constituyen núcleos especialmente estimulantes del quehacer creativo de la literatura". Citado por Pizarro $(1985,64)$.

${ }^{6}$ Desarrollamos el estudio de la obra como sistema en varios niveles: acción o estructura profunda, intriga o estructura superficial, aspecto verbal (modo, tiempo y punto de vista) y aspecto semántico (ćrmo significa y qué significa la obra). Todo texto se integra a un sistema teatral y éste a su vez se relaciona dialécticamente con la serie social.

7 Para Villegas (1982, 25 y ss..) la acción dramática es una abstracción, no un hecho concreto: "es un esquema dinámico que se distiende a partir de una situación inicial conflictiva". Cfr. Gouhier (196-7, 62 y ss.). Pavis propone acertadamente a nuestro criterio, a la acción como "un elemento transformador y dinámico que permite pasar lógica y temporalmente de una situación a otra" (1983, 5 y ss.), y advierte que el modelo actancial (Greimas, Barthes, Todorov) reconstituido en las distintas secuencias de la obra, posibilita apreciar cómo se genera la acción y cómo cambia la relación sujeto-objeto/ ayudanteoponente.
} 
misión y es al mismo tiempo su más brutal oponente. Durante el desarrollo y el desenlace de la acción, se asiste a los sucesivos desempeños del sujeto que terminan en otros tantos fracasos por conseguir su objetivo.

En el plano de la intriga o estructura superficial ${ }^{8}$, además de la mencionada tensión entre los dos principios constructivos, se destaca la invención de un "personaje fracasado", que busca cambiar su realidad y la de su entorno, pero no tiene ni las fuerzas ni la posibilidad de hacerlo, enfrentado a la sociedad, que finalmente lo destruye.

El modelo, que desde el punto de vista del discurso teatral asume la lengua popular, con sus variantes e indefiniciones, fue en su momento interpretado por actores que unian a su técnica finisecular procedimientos usados por el actor europeo. Este intérprete, especialmente en el Río de la Plata, cuyo modelo era Pablo Podestá, era capaz de hacerse cargo con propiedad de papeles actorales diversos.

Está claro que esta modernización de principios de siglo fue posible porque en las ciudades mencionadas había aparecido un público nuevo, el de la naciente clase media, que reclamaba un módico espejo de su vida, realista o idealizado, en la comedia de costumbres. Había surgido también una crítica cuyo horizonte de expectativa coincidía con las convenciones y con la semántica del género, que consistía en una determinada concepción liberal-positivista que pretendia, sin conseguirlo, instaurar al teatro como práctica social.

El drama de ideas de principios de siglo, con su peculiar punto de vista concretado en un desarrollo dramático destinado a probar una tesis realista que pusiera de manifiesto las fallas del sistema político-social, había evolucionado a principios de la década del veinte en un teatro comercial, que en países como Argentina se había consolidado junto a formas teatrales populares. Este subsistema teatral tendía, a fines de la década, a automatizarse. Esto era advertible a partir de la aparición de un teatro meramente epigonal y el surgimiento de nuevas tendencias que pretendian terminar con el teatro comercial apelando a los modelos europeos.

2. Contra el subsistema teatral realista costumbrista se alza la modernización de mediados de la década del veinte. Decimos modernización y no vanguardia, porque en la producción inicial de autores como Discépolo, Samuel Eichelbaum, Francisco Defilippis Novoa, en Argentina; Celestino Gorostiza, Xavier Villaurrutia y Roberto Usigli en México, y entre otros Emilio Beleval en Puerto Rico, Armando Moock en Chile y Luis Osorio en Colombia, no encarna el cuestionamiento y el intento fallido de destruir la institución teatro (Bürger 1987), sino todo lo contrario. Esta tendencia, que asumía lo europeo

\footnotetext{
8 "La intriga, en oposición a la acción, es la sucesión detallada de los surgimientos de la fábula, el entrelazamiento y la sucesión de los conflictos y de los obstáculos y de los medios en marcha para superarlos. Describe el aspecto exterior, visible de la progresión dramática, y no los movimientos de fondo de la acción interior" Pavis $(1983,277)$.
} 
como modelo absoluto, postulaba la instauración de un macrosistema culto que afirmara una dramaturgia que se consideraba, en la mayoría de nuestros países, todavía no consolidada.

Lo mismo puede decirse del movimiento de teatro experimental o independiente ${ }^{9}$ del sistema comercial, que en algunos casos se instaló en nuestras universidades y en otros, como en la Argentina, se mantuvo absolutamente equidistante de las instituciones oficiales. En 1928 aparece en México el Teatro Experimental Ulises, creado por Villaurrutia, Novo y Gorostiza, y en 1930 el Teatro del Pueblo en Argentina, fundado por Leonidas Barletta. Estos teatros no comerciales no tardaron en extenderse a toda América Latina, especialmente a Chile, con el Teatro Experimental de la Universidad Católica (1941), y al Uruguay, con el Teatro del Pueblo (1937) ${ }^{10}$.

Los caracteres de estos nuevos grupos, tomando como modelo el Teatro del Pueblo de Buenos Aires, se pueden sintetizar a partir de la noción de "movimiento", que incluía la abolición del concepto de escuela y privilegiaba el activismo de sus miembros organizados a partir de la noción de "grupo", con comisiones directivas, asambleas, entes de lectura, tesorería, etc., y "antagonismo", contra la tradición anterior, especialmente contra el teatro comercial y sus lugares comunes: la primera figura, el empresario, el pago por las actuaciones, etc. Esta mística, esta militancia, implicaba también en muchos casos un nihilismo que negaba absolutamente el teatro anterior, el viejo sistema. Se intentaba, desde el texto espectacular, construir un sistema nuevo a partir de la puesta en escena de autores extranjeros desconocidos en el país, clásicos y modernosy, más adelante, en las décadas del cuarentay el cincuenta, de técnicas de actuación innovadoras. Por otra parte, desde el principio se entronizó al director de escena como orientador estético e ideológico del grupo y al escenógrafo como uno de sus principales colaboradores.

También se puede encontrar en el modelo propuesto una concepción "agonista" del teatro, una suerte de búsqueda inconsciente de la autodestrucción o el sacrificio personal en pos del éxito futuro del movimiento (Poggioli 1964).

\footnotetext{
${ }^{9}$ Grinor Rojo $(1972,49)$ denomina a este teatro como de imaginación. Dauster ha llamado a sus autores experimentales $(1973,21)$ y Arrom, vanguardistas $(1963,19)$.

${ }^{10}$ Más allá de los testimonios del propio Barletta (1960), y de los historiadores del teatro independiente en Buenos Aires (Marial, 1955), son muy clarificadoras las recientes declaraciones de la directora Mané Bernardo, integrante en ese período del Teatro de la Cortina (un núcleo experimental concretado a partir del luego germinal Teatro del Pueblo): "Trabajé durante diez años en el Teatro de la Cortina, tiempo en el que representamos unas 250 obras. Las piezas no eran de autores argentinos porque lo que intentabamos por esa época era darle jerarquía al repertorio, al director, al escenógrafo. El repertorio nacional en la esfera profesional era muy pobre, sólo se escribían sainetes; el que dírigía la compañía en el mejor de los casos, era la primera figura, el capocómico, o no habia dirección, los decorados eran telones pintados, que se alquilaban. Del otro lado estaban los artistas como Saulo Benavente ... que querían aportar sus ideas renovadoras" (Teatro, IV, no.13 /julio 1982/).
} 
Estos rasgos implicaban una idea didáctica del teatro, que intensificaba una constante de nuestro sistema teatral desde sus comienzos: la educación del pueblo a través, no sólo de los cambios mencionados, sino también de la publicación de revistas de los grupos, exposiciones de plásticos, conferencias y estrenos aislados de autores locales provenientes de la literatura, pues los autores comerciales eran considerados un verdadero "caso perdido", que debían orientar a los espectadores hacia un mejoramiento individual y social.

Los autores mencionados al principio, tomaban los modelos europeos y norteamericanos: Pirandello, Strindberg, Lenormand, O'Neill y el expresionismo. Se hacían cargo así de la desintegración del positivismo europeo incluida en el pensamiento de Henri Bergson (la intuición como única posibilidad de conocimiento y la idea de duración de los momentos vividos), de Sigmund Freud (a partir de sus teorías se había fundado un denominado teatro del inconsciente, con su base en los sueños, los actos fallidos y el psicoanálisis), y Federico Nietzsche (su vitalismo y su nihilismo).

El intento de textos como María la Tonta (1927), de Francisco Defilippis Novoa, En tu vida estoy yo (1934), de Samuel Eichelbaum; Trescientos millones (1932) y Saverio el cruel (1936), de Roberto Arlt; El ausente (1937), de Xavier Villaurrutia, consiste en incluirse dentro de un nuevo macrosistema teatral en contacto con el mundo. Estos autores pugnan por ser la continuación del sistema europeo, pero lo hacen de manera diversa a lo que había ocurrido hasta ese momento: quieren que el estímulo externo actúe solo, sin la consabida mezcla con el sustrato finisecular. De esta manera, los mencionados modelos europeos y norteamericanos funcionan en esta primera fase del macrosistema que abarca desde 1925 hasta 1960, como productores directos de convenciones. Un ejemplo aclarará lo que decimos: es el del teatro de Roberto Arlt, quien en la década del treinta continúa ahondando la veta semántica que descubriera Pirandello. Trabaja como un complemento del autor italiano. Tiene una gran capacidad para concretar variantes, y es evidente que, como autor, está convencido de que su obra dramática tiene más que ver con el teatro europeo que con el teatro argentino anterior.

Pero esa aspiración es imposible de cumplir, ya que las transgresiones de estos autores casi siempre se concretan sobre los artificios de los géneros finiseculares, a los cuales les cambian su funcionalidad, como ocurre con el tratamiento del concepto de tesis realista y los artificios del encuentro personal y el melodrama. Sin embargo, la poética consciente de estos autores era otra; su utopía coincidía con la del mencionado movimiento de teatro independiente y del teatro comercial culto: aplicar el nihilismo con relación a la tradición latinoamericana.

El modelo de esta primera fase, que postula la modernización como ruptura, se puede sintetizar de la siguiente manera:

A nivel de la estructura profunda, se caracteriza por la presencia de sequencias breves: un teatro de organización fragmentaria. El objeto del deseo 
del sujeto ha dejado de ser algo concreto - la honra social, el dinero o el amorpara pasar a ser una "abstracción simbólica". En María la Tonta es el amor a la humanidad, en Saverio el cruel y Trescientos millones, el fracaso de la concreción de un sueño; en $E l$ ausente, la negación del mundo exterior.

Estas características se reflejan en el nivel de la intriga; se producen pequeñas alteraciones en el modelo aristotélico de principio-medio-fin. La historia aparece aparentemente desarticulada y se presenta en cuadros breves a partir del procedimiento de la elipsis. La prehistoria está muy limitada, el texto segundo aparece dramatizado y literaturizado y la causalidad ha dejado de ser explícita en la mayor parte de los casos.

El sistema de personajes incluye dos tipos diferentes de actores: "sufrientesfarsantes"; "personajes simbólicos-personajes tipos"; "personajes realistaspersonajes fantásticos", turnándose en la ocupación del centro y la periferia de la acción. Asimismo, se observa la inclusión de un artificio: el efecto de simultaneidad, especialmente en el texto de Eichelbaum. Consiste en un corte en la cadena sintagmática; se trata de teatralizar el tiempo subjetivo según el concepto de Bergson. Así, los tradicionales apartes funcionan como monólogos interiores, concretando una diversidad de puntos de vista que transmiten el estado anímico de los personajes.

En general, se limita la acción exterior y María la Tonta, y los textos de Arlt se estructuran alrededor de un protagonista que no actúa y que si lo hace, tiene poco efecto en el desarrollo de los hechos de la intriga.

El drama se ha vuelto subjetivo, confesional. Es la semántica del expresionismo subjetivo "...la dramatización del aislamiento y la vulnerabilidad: el grito del individuo extraviado en un mundo sin sentido" (Williams 1982, 163).

Esta primera versión del sistema teatral, que plantea la modernización como ruptura con los modelos finiseculares a partir de nuevas aportaciones europeas, coincide con la afirmación de las principales ciudades latinoamericanas comograndes urbes, a partir de tensiones entre modernidad europea y diferencia latinoamericana, angustia, criollismo y vanguardia, cultura de mezcla (Sarlo 1988, 13-94).

El campointelectual de estas ciudades se hallaba consolidado, lo mismo que el público de la clase media. Este público, que había conseguido en algunos países el acceso al poder por medio de sus representantes, poseía "su biblioteca" y había formado sus gustos literarios y teatrales en contacto con la cultura europea y norteamericana.

Sintetizando: la primera fase del subsistema teatral, originado en los veinte dentro del sistema teatral latinoamericano, propone una modernización que intenta poner en contacto con el mundo sus producciones textuales. Parte de un planteo de ruptura, pero se concreta en una práctica teatral reformista. Implica un momento de culturalización, de entrada de nuevos modelos dramáticos y teatrales. 
Años después, en los cincuenta - durante la segunda fase de este subsistema teatral-se apreciarían, ya nacionalizados, los efectos de esta "culturalización": la concreción de una verdadera tradición de "teatro culto moderno", el afianzamiento de un nuevo tipo de autor, de director, de actor, de critica y de público, la desaparición del teatro popular y la definitiva ubicación del sistema viejo del realismo-costumbrismo en la categoría de remanente. 


\section{BIBLIOGRAFIA}

Altamirano, C. y Sarlo, B., Ensayos argentinos, Buenos Aires: CEAL, 1983. Arrom, José, Esquema generacional de las letras hispanoamericanas. Ensayo sobre un método, Bogotá: Caro y Cuervo, 1963.

Barletta, Leónidas, Viejo y nuevo teatro, Buenos Aires: Futuro, 1960.

Bürger, Peter, Teoría de la vanguardia, Barcelona: Península, 1987.

Dauster, Frank, Historia del teatro hispanoamericano, 2da. edición. México: De Andrea, 1973.

De Toro, Fernando, "Reflexiones en torno a la historia literaria y del teatro hispanoamericano", Gestos, I, 1, (abril 1986): 101-120.

Fowler, Alaistair, "The Life and the Death of Literary Forms", New Literary History, II, 2, (Winter 1971).

Gouhier, Henri G., La obra teatral, Buenos Aires: Eudeba, 1961.

Guillén, Carlos, Literature as System. Essays toward the theory of Literary History, Princeton: Princeton University Press, 1971.

Marial, José, El Teatro Independiente, Buenos Aires: Alpe, 1955.

Pavis, Patrice, Diccionario de teatro, Barcelona: Paidós, 1983.

Pizarro, Ana, Neohelicon, X12, Academia Kiado, John Benjamins B.V., 1984. La Literatura latinoamericana como proceso, Buenos Aires: CEAL, 1985.

Poggioli, Renato, Teoría del arte de vanguardia, Madrid Revista de Occidente, 1964.

Rojo, Grinor, Orígenes del Teatro Hispanoamericano Contemporáneo, Valparaiso: Ediciones Universitarias de Valparaíso, 1972.

Sarlo, Beatriz, Una modernidad perisférica 1920-1930, Buenos Aires: Nueva Visión, 1988

Tinianov, Juri, Avanguardia e Tradizione, Bari: Dedalo 1968. "Sobre la evolución literaria", Todorov(compilador) Teoría de la literatura de los formalistas rusos, Buenos Aires: Signos 1970.

Villegas, Juan, Interpretación y análisis del texto dramático, Ottawa: Girol Books, 1982.

Teoría de la historia literaria y poesía lírica, Ottawa: Girol Books, 1984.

Williams, Raymond, Cultura. Sociología de la comunicación y el arte, Barcelona: Paidós, 1982. 